3-1-2017

\title{
Spotlight on the integrated primary care special interest group
}

\author{
Kathryn W. Hoffses \\ Thomas Jefferson University \\ Andrew R. Riley \\ Oregon Health and Science University \\ Kathryn M. Menousek \\ University of Nebraska Medical Center \\ Kriston B. Schellinger \\ Rady Children's Hospital, San Diego \\ Allison O. Grennan \\ University of Nebraska Medical Center
}

Follow this and additional works at: https://jdc.jefferson.edu/pedsfp

See next page for additional authors

Part of the Pediatrics Commons, and the Psychiatry and Psychology Commons

Let us know how access to this document benefits you

\section{Recommended Citation}

Hoffses, Kathryn W.; Riley, Andrew R.; Menousek, Kathryn M.; Schellinger, Kriston B.; Grennan, Allison 0.; Cammarata, Chrissy; and Steadman, Jason L., "Spotlight on the integrated primary care special interest group" (2017). Department of Pediatrics Faculty Papers. Paper 72. https://jdc.jefferson.edu/pedsfp/72

This Article is brought to you for free and open access by the Jefferson Digital Commons. The Jefferson Digital Commons is a service of Thomas Jefferson University's Center for Teaching and Learning (CTL). The Commons is a showcase for Jefferson books and journals, peer-reviewed scholarly publications, unique historical collections from the University archives, and teaching tools. The Jefferson Digital Commons allows researchers and interested readers anywhere in the world to learn about and keep up to date with Jefferson scholarship. This article has been accepted for inclusion in Department of Pediatrics Faculty Papers by an authorized administrator of the Jefferson Digital Commons. For more information, please contact: JeffersonDigitalCommons@jefferson.edu. 


\section{Authors}

Kathryn W. Hoffses, Andrew R. Riley, Kathryn M. Menousek, Kriston B. Schellinger, Allison O. Grennan, Chrissy Cammarata, and Jason L. Steadman 
National healthcare initiatives such as the Patient-Centered Medical Home (PCMH) and Affordable Care Act (ACA) have placed renewed emphasis on identification and delivery of cost-effective, efficient, and quality health care services in primary care settings (Rozensky, 2014). These important pieces of legislation have called for increased integration of physical and behavioral health services with additional funding for early detection and intervention for behavioral health problems, focus on high-need populations, and increased emphasis on teambased care to improve patient experience, clinical services, and to reduce cost. Pediatric psychologists are well positioned to address the needs of children and families in this setting through their unique expertise and knowledge of family systems and strategies to promote child mental health and behavior change. Integrating psychologists into pediatric primary care (PPC) environments is not a new entity (Schroeder, 1979; Schroeder, Goolsby, \& Stangler, 1975; Wilson, 1964), but only recently has application of psychologists in primary care become more widespread (Rozensky, 2014; Rozensky \& Janicke, 2012; Tynan \& Woods, 2013).

This momentum was reflected in the establishment of the Integrated Primary Care Special Interest Group (IPC SIG) in 2014. Initially, the Board of Directors of the Society of Pediatric Psychology (SPP) appointed an IPC Task Force consisting of senior psychologists with experience developing integrated care programs for university and hospital-based psychology training sites with the task of creating a network of professionals to assist in refining standards for professional competency, assisting in development of training models, and encouraging evidence-based approaches to service delivery (Sturm \& Stancin, 2013). Shortly following the development of the IPC Task Force, this group sought formal recognition as a SIG through SPP. The IPC SIG quickly expanded and currently includes 150 professionals and trainees from across 
the country with a range of professional experiences working in PPC settings. As the SIG expanded, members noted interest in better understanding their colleague's practices in PPC.

Since its inception, the IPC SIG has yielded a number of notable products including a manuscript outlining professional competencies for psychologists seeking to practice in PPC (Hoffses et al., 2016), a directory of primary care internship and fellowship training opportunities, a newsletter that is distributed biannually highlighting research findings unique to primary care, summaries highlighting ways to improve primary care practice (i.e., AHRQ), and interviews with noted psychologists providing recommendations for professional development (i.e., how to write more effectively) and perspectives on the future of primary care psychology. A plethora of networking opportunities (i.e., through conferences and SIG communication networks) has also been made available to SIG members. In addition, our SIG has the opportunity to emphasize the many training opportunities that are available to enhance service delivery in primary care. Conferences facilitated by SPP and Collaborative Family Healthcare Association (CFHA) provide opportunities for SIG members to connect; new meetings conducted by Geisinger Health System, Montefiore Medical Center, and the Munroe Meyer Institute at the University of Nebraska Medical Center have also provided opportunities for members to connect and learn the latest developments for service provision in primary care. Finally, the IPC SIG has initiated a mentorship program in which early-career psychologists or psychologists at other stages of professional development who are interested in implementing IPC models are matched with senior and experienced IPC psychologists to discuss program development, practice, billing, and training challenges.

The survey project presented in this issue, Professional Practices, Training, and Funding Mechanisms: A Survey of Pediatric Primary Care Psychologists, exemplifies the spirit of 
collaboration and productivity fostered through the IPC SIG. The project had its beginning at the IPC SIG meeting at the Society for Pediatric Psychology annual conference (SPPAC) in 2015. During the course of this meeting, members of the SIG voiced a desire to learn more about their colleagues' practices in primary care. While PCMH and ACA have brought a wealth of opportunity, these documents have also ushered in a host of questions and logistical concerns. What kind of training do psychologists need to meet the demands of this growing market? Which models of integration work best and for whom? How will services get reimbursed? What do we mean by "integrated" care? The empirical literature has accelerated with regards to demonstrating the efficacy of IPC services (Asarnow, Rozenman, Wiblin, \& Zeltzer, 2015), but it is often unclear how integration plays out in everyday practice given diverse training backgrounds, clinical settings, and payer circumstances. Kindled by IPC SIG leadership, a small group of members began collaborating to address these questions. Through months of emails, conference calls, and conferring with colleagues, our team collaboratively identified study objectives, created and refined a survey instrument, and collected data from psychologists working in PPC. The IPC SIG email listserv and a directory of training programs offering primary care experiences, both products of the IPC SIG, served as essential recruitment tools. These efforts would not have been possible if the IPC SIG had not been established and illustrate how the IPC SIG has provided a foundation for national collaboration and growth of knowledge among members and those practicing in primary care.

As opportunities in primary care are rapidly growing for psychologists across the nation, so are the possibilities for participation in the IPC SIG. Members of the IPC SIG are provided with the opportunity to network with other professionals to refine competency standards, training models, approaches to service delivery, to receive education on health care reform and the 
changing landscape for practice and funding sources, to explore how pediatric psychologists bring unique skills to PPC settings (i.e., screening, triage, consultation, intervention, interprofessional training), and how their role coincides with the roles of pediatric psychologists in other health care delivery systems (e.g., tertiary care). Members are encouraged to collaborate on research efforts so as to contribute to the evidence base for primary care services in addition to pursuing opportunities for advocacy at state and national levels, as well as among other APA divisions (e.g., Health Psychology) and governance groups (e.g., APA Division of Integrated Care). Authors of this manuscript all represent early career professionals thus highlighting the unique opportunities for early career psychologists to play a pivotal role in this organization and advancing knowledge for services in primary care. Opportunities are also available for students interested in working in primary care to pursue a leadership position within the SIG and become involved in writing articles for our newsletter, participating in research groups, and receiving mentorship for additional exposure to this exciting field. Those interested in joining the IPC SIG need an active membership with SPP. If interested please contact Karen Roberts (apadiv54@gmail.com) who will verify your membership and forward your interest in joining the SIG to our Membership Chair, Allison Grennan (Allison.Grennan@unmc.edu). 


\section{References}

Asarnow, J. R., Rozenman, M., Wiblin, J., \& Zeltzer, L. (2015). Integrated medical-behavioral care compared with usual primary care for child and adolescent behavioral health: A meta-analysis. JAMA Pediatr, 169(10), 929-937. doi:10.1001/jamapediatrics.2015.1141

Hoffses, K. W., Ramirez, L. Y., Berdan, L., Tunick, R., Honaker, S. M., Meadows, T. J., ... \& Stancin, T. (2016). Topical Review: Building Competency: Professional Skills for Pediatric Psychologists in Integrated Primary Care Settings. Journal of Pediatric Psychology, 41(10), 1144-1160.

Rozensky, R. H. (2014). Implications of the affordable care act for education and training in professional psychology. Training and Education in Professional Psychology, 8(2), 8394.

Rozensky, R. H., \& Janicke, D. M. (2012). Commentary: Healthcare reform and psychology's workforce: Preparing for the future of pediatric psychology. Journal of Pediatric Psychology, 37(4), 359-368. doi:10.1093/jpepsy/jsr111

Schroeder, C. S. (1979). Psychologists in a private pediatric practice. Journal of Pediatric Psychology, 4(1), 5-18.

Schroeder, C. S., Goolsby, E., \& Stangler, S. (1975). Preventive services in a private pediatric practice. Journal of Clinical Child Psychology, 4(3), 32-33.

Sturm, L. \& Stancin, T. (2013). Competencies for pediatric psychology practice in primary care: A work in progress. CYF News. Retrieved from http://www.apa.org/pi/families/resources/primary-care/competencies.aspx.

Tynan, W. D., \& Woods, K. E. (2013). Emerging issues: Psychology’s place in the primary care pediatric medical home. Clinical Practice in Pediatric Psychology, 1(4), 380-385. 
Wilson, J. L. (1964). Growth and development of pediatrics: Presidential address-1964." The Journal of Pediatrics, 65(6), 984-991. 